Margo Bargheer and Kizer Walker*

\title{
Library Publishing and the University Press in the United States and Germany: Lessons from Two Academic Contexts for Sustaining the Scholarly Book
}

https://doi.org/10.1515/bfp-2017-0037

\begin{abstract}
Many academic libraries have embraced an active publishing role in recent years, an important component in libraries' efforts to address mounting pressures throughout the scholarly communications cycle. Libraries in the United States and Germany have been especially assertive in this arena. This article focuses on one particular aspect of libraries' publishing efforts in Germany and the U.S.: interventions to make the production and dissemination of the scholarly book (in print and electronic formats) more economically sustainable and its content more open. This article discusses the role of the scholarly book for early-career researchers in the humanities and social sciences and reflects on intercontinental differences. The article considers the library efforts in the context of broader, university-based publishing activities in both national contexts, particularly the relationship of library publishing and university presses. The authors discuss how differences and commonalities between the academic and economic contexts in the U.S. and Germany have led to institutional responses that diverge and converge in significant ways and they suggest that such a comparison can usefully inform scholarly communications strategies in both countries. The article considers broad national trends and also draws on examples from the authors' home institutions: the State and University Library at Göttingen and Cornell University Library in Ithaca, New York.
\end{abstract}

Keywords: United States; scholarly communications; university press; library publishing; Cornell University; Göttingen University; open access; monograph

\section{Verlegerische Dienste an Bibliotheken und Universitäts- verlage in den U.S. A. und Deutschland: Unterschiede und Gemeinsamkeiten beim Publizieren wissenschaftlicher Bücher}

Zusammenfassung: In den letzten Jahren haben zahlreiche wissenschaftliche Bibliotheken mit ihren Publikationsdiensten verlegerische Verantwortung übernommen und reagieren damit auf zunehmende Probleme des wissenschaftlichen Kommunikationssystems. Bibliotheken in den USA und Deutschland sind dabei besonders aktiv. Dieser Artikel geht dabei einem besonderen Aspekt der bibliothekarischen Publikationsdienste nach: Wie können wissenschaftliche Infrastrukturen Produktion und Verbreitung des wissenschaftlichen Buches (in Print und elektronischen Formaten) ökonomisch nachhaltig gestaltet und deren Inhalte möglichst frei verfügbar gemacht werden? Außerdem diskutieren wir die Rolle des wissenschaftlichen Buches für die wissenschaftliche Karriere in den Geistes- und Sozialwissenschaften im interkontinentalen Vergleich. Der Artikel stellt diese bibliothekarischen Publikationsaktivitäten in ihren nationalen Kontexten dar und geht besonders auf Universitätsverlage ein. Dabei arbeiten wir heraus, wie Unterschiede und Gemeinsamkeiten der akademischen und ökonomischen Rahmenbedingungen in den USA und Deutschland sich in den jeweiligen Infrastrukturen abgebildet haben, um über diesen Vergleich sinnvoll voneinander lernen zu können. Der Artikel geht auf übergreifende nationale Trends ein und verdeutlicht diese mit Fallbeispielen aus den Institutionen der Autoren: der Niedersächsischen Staats- und Universitätsbibliothek in Göttingen und der Universitätsbibliothek Cornell in Ithaca, New York.

Schlagwörter: USA; Wissenschaftskommunikation; Universitätsverlage; Library Publishing; Cornell University; Universität Göttingen; Open Access; wissenschaftliches Buch 
Inhalt

1 Introduction.................... 292

2 The first book in contemporary U. S. and German academic careers . . . . . . . . . . . . . 292

3 University presses in the United States . . . . . . 295

4 University presses in Germany . . . . . . . . . . 297

5 University publishing at University of Göttingen . 299

6 University publishing at Cornell . . . . . . . . . 301

7 Solutions at scale? . . . . . . . . . . . . . 302

8 Conclusion.................... 305

\section{Introduction}

Academic libraries have a long history of functioning, in certain limited contexts, as scholarly publishers. Yet in the past 15-20 years, enabled by the internet and world wide web, the volume of publishing activity and the number of libraries internationally that are involved in the direct, public dissemination of new scholarly information has grown precipitously. The internet's disruption of print publishing models has introduced several countervailing dynamics that, in the uneven transition to digital, have led libraries to a more active publishing role. The outlines of this context are well known. Common office technologies enabled authors and editors to deliver ready-to-publish documents and, at least in theory, become independent of the expert system of publishing. Electronic delivery seemed to allow fast and easy access for everyone. Yet, at the same time, electronic delivery and the internet also accelerated consolidation of commercial academic publishing and spiraling prices, dealing repeated blows to library budgets. This same electronic environment brought the core library practices of collection and storage together with powerful platforms for distribution and began to erase the distinction between collecting and disseminating (e.g., institutional repositories are simultaneously institutional publishing channels). And pressures created by price escalation fueled libraries' embrace of alternative modes of scholarly communication. Libraries' proposed solutions have had a strong emphasis on open access models to disseminate scholarly literature as directly as possible by bypassing traditional intermediaries and license barriers.

Early library efforts in the publishing sphere focused largely on informal publication, leaving certification processes to other entities, either within academia or with the expert system of professional publishers. Although books have featured in libraries' open access publishing initiatives from the beginning (see Bargheer and Pabst 2016), by far the majority of attention has until recently been directed to journal articles and similar works: retaining rights to store versions of published articles in institutional repositories, dissemination of preprints, etc. This focus on shortform scholarship responds to the serials pricing crisis and also represents a more manageable format for readers and publishers.

But what of the scholarly book, the monograph, which is under great pressure of its own? Here comparison of the situations in Germany and the United States may shed new light on pressures and possibilities on both sides. We offer a qualitative overview, drawing on experiences from our two institutions - both of which have a history of leadership in the library publishing space - and recent developments in the field. Our focus in this article is specifically on libraries' shifting relations with university presses - dedicated publishing units within the academic institution with emphasis on the book. Sustainability of the scholarly book is problematic in the U.S. and Germany, but while some of the pressure points are shared, others are specific to the respective academic context.

\section{The first book in contemporary U.S. and German academic careers}

Given its role in establishing academic reputations, especially in humanistic and qualitative social scientific fields, it is useful to look at the first book - i.e., the initial book published in a scholar's career - as a gauge of pressures in academic publishing and a point of intervention for libraries as publishing partners. While researchers in the natural sciences rely almost exclusively on (digital) journal articles to establish their research profile, for large parts of the humanities and qualitative social sciences, the ability to marshal the "long argument" and to publish it in the form of a printed monograph remains the standard that establishes the serious scholar, and this is directly reflected in tenure and recruitment procedures. This much is true in both the U.S. and German contexts, but the interplay of different institutional norms and practices and the economics of publishing has created divergent outcomes.

In the United States, book publishing is tied closely to promotion and tenure for those academics that are eligible for tenure, particularly in the social sciences and humanities, and particularly at larger research universities. In these settings, a published book is generally a minimum requirement for promotion from assistant to associate professor; failure to achieve tenure usually means loss of 


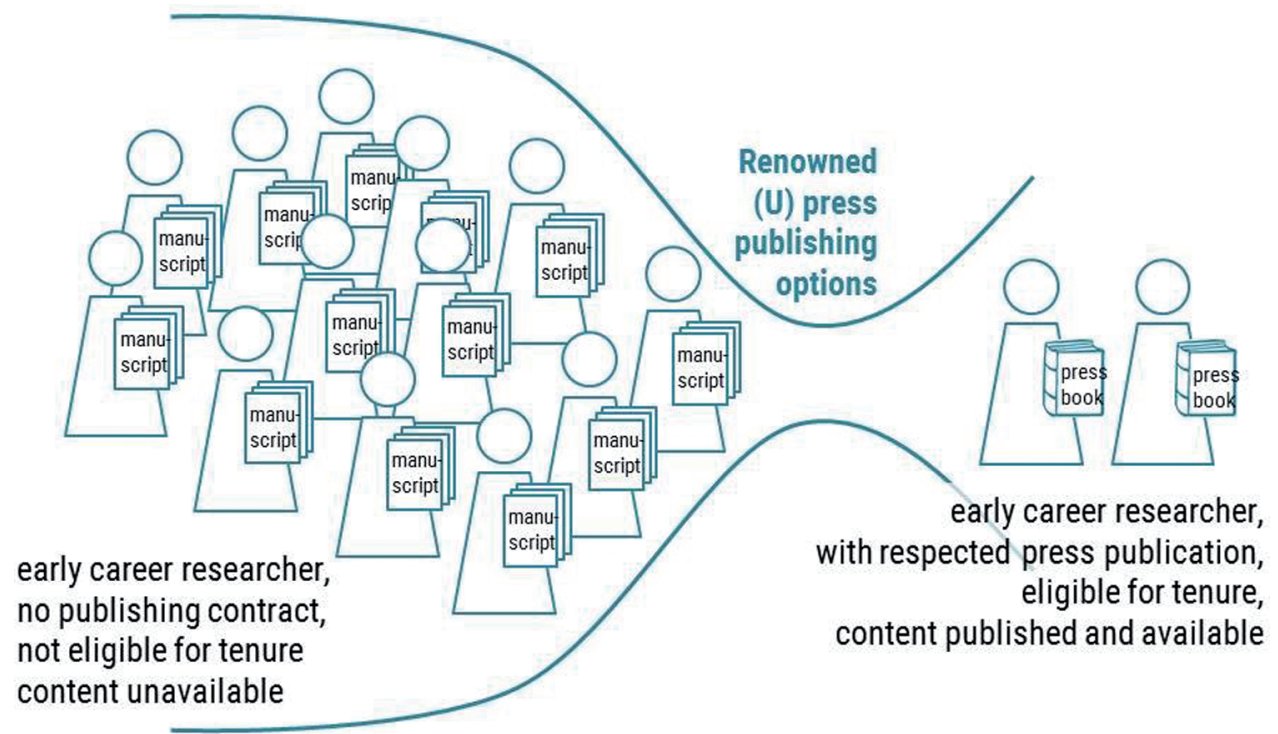

Fig. 1: Publishing options in the conventional paradigm

position. The first book - the tenure book - is normally derived from the dissertation, but only after it has undergone significant revision over a period of years, during which the author is employed as a professional scholar. University presses play a crucial role in this process, but not primarily by publishing scholarship produced at the institutions of which they are a part; instead presses compete for the best monograph manuscripts nationally, even internationally. The stages of the transformation of dissertation to book take place in the context of a peer review process that is coordinated by the presses and through authors' work with press editors. ${ }^{1}$ As such a process is costly, presses must be sure to take only as many manuscripts on board as they can process with the given resources. All of these aspects pose specific challenges for early-career researchers. The bottleneck of publishing options in acceptable presses has an influence on their tenure options, while their content remains widely unavailable to their peers and thus has limited impact on the current scholarly discourse. ${ }^{2}$

1 A recent study of University press publishing costs cites acquisitions work (including author communications/support, developmental editing, and coordination of the peer-review process) as the single most expensive of UPs' core publishing functions. Maron et al. (2016). See also the discussion by Sandy Thatcher (former director of Penn State UP) on the costs of proactive list building via acquisition and solicitation: We have shortened long links in our article via bitly. See scholarly kitchen http://bit.ly/2vJfVtL.

2 See Muller (2016). She presented a fierce talk before university press representatives revealing what usual press workflows (e.g., requiring exclusive submission and slow processing due to limited
U.S. university presses receive subsidies from their institutions, but these have shrunk over time and typically cover only a small fraction of costs, which presses are expected to earn back mainly through sales. While some U.S. universities offer subsidies for books (especially first books) published by their faculty members, and these funds flow to university presses at other institutions, this practice is limited and not systematic. In general, the humanities and qualitative social sciences in the U.S. do not have a culture of author payments for book publishing and, in certain contexts, author payment can carry a negative stigma. Academic libraries have traditionally been university presses' primary customers, but as library book budgets have stagnated, sales have dropped, forcing presses to pursue a number of alternative strategies aimed at making up for lost sales revenues. Presses increasingly rely on books marketed to an educated, non-academic audience to bear the cost of publishing specialized scholarship, but as book lists have shifted emphasis, the space for highly specialized academic books has shrunk.

In the German context, an academic's first published book in the humanities, qualitative social sciences, and legal studies is typically the doctoral dissertation itself, as making the thesis publicly available is mandatory in order for the degree to be granted. ${ }^{3}$ University libraries play an

resources) can mean for their potential early-career authors seeking tenure.

3 Granting doctoral degrees requires German universities to issue mandatory rules (Promotionsordnungen) for doctoral candidates stipulating that their thesis must be publicly available (http://bit.ly/2iz $\mathrm{NTrB}$; shortened link to "Grundsätze für die Veröffentlichung von 
important role in the process as they have to integrate numerous dissertations in their indexing and archiving system and disseminate them to partner libraries. The most selective publishers compete for the best dissertations, others are placed along a quality spectrum with renowned, discipline-specific academic publishers on one end, and mere dissertation presses offering copy shop-like printing services on the other end, with newer university presses still finding their position in the spectrum. These university presses are usually part of the university's service portfolio and often act as "embedded publishers," run by the library. This functional and institutional characteristic distinguishes German university presses from their namesakes in the Anglo-American sphere. The following example highlights the challenge that a library-based publishing service has to reflect on, beyond solving technical or organizational obstacles.

With the advent of the internet, several German universities started online platforms to offer their $\mathrm{PhD}$ candidates affordable alternatives to press publications and at the same time lower the space and organizational pressures that printed dissertations, in particular, pose for libraries. ${ }^{4}$ The online platform for Göttingen University is the "eDiss" dissertation server, an open access repository holding more than 6,300 dissertations from all 13 faculties since it started in 1996. Especially the STM fields quickly adopted this option - their main communication with their communities took and takes place in journal articles anyway, lowering the importance of the thesis as such. Within Göttingen's four book-oriented disciplines (humanities, theology, law, and social sciences) 429 dissertations were completed during the period of 2012 to 2015. Of these, 85 were published online open access via eDiss, 344 in the above

Dissertationen”, Kultusministerkonferenz 1997). The requirement of public availability can be satisfied by placing the thesis in an online repository, printing it in defined numbers and disseminated through library exchange programs or publishing it with a recognized press. $\mathrm{PhD}$-granting institutions in the U.S. also required publication of the dissertation through the early 20th century, but the practice was gradually dropped in the 1930's and 40's; see Meisel (2010).

4 Most large research libraries in the U.S. host electronic theses and dissertations (ETDs) in their institutional repositories, although embargoes or other access limits may apply. The library-based service replicates, in some ways, the commercial system that grew up around the dissemination of dissertations in microform. University Microfilms Inc. (UMI), founded in the 1930's, evolved into the company now known as ProQuest. UMI/ProQuest continues to play a key role in registering dissertations for many U.S. PhD-granting institutions; see Clement and Rascoe (2013). The role of library-based ETDs in the U.S. is quite different than in the German context, however, since these unrevized theses are not considered book publications.

5 ediss.uni-goettingen.de, based on DSpace. mentioned presses. Social sciences saw 74 finished dissertations with 41 of these finding their way on the eDiss repository, while law graduates with their rather conventional publishing behavior did not use eDiss at all during those years. For the same period however, 28 law theses appeared in Göttingen University Press, which is a unit of the Göttingen State and University Library. All are available open access - which is mandatory for authors of the press and in print with an ISBN for the book market. Often we see that discussions on the acceptance of new forms of publishing in the humanities and qualitative social sciences run along the dichotomy of print vs. digital. Our example indicates that we need to rethink that dichotomy. Publishing takes place in certain publication cultures that include reputation-building processes drawing on discipline-specific author and reader expectations. Conventional publishing expectations, as in the case of legal studies at Göttingen, do not seem to clash with digital formats. Rather, they seem to run along formal vs. informal lines, the former associated with press-specific workflows (corporate design, branding, conventional dissemination, toll access) that seem to serve as tokens for selectivity and quality.

But are these author and reader expectations of pressrelated quality assurance in line with reality? At Göttingen University Press we have worked with several scholars that confirmed an overall observation for the German publishing landscape: the higher a book's degree of specialization, the more likely it is to pass through the value chain at professional publishing houses without any significant improvement beyond professional dissemination and marketing. These books tend to be published as delivered, meaning that authors and editors deliver "camera ready versions" to publishers and organize proof-reading, copyediting, formatting or translations either within their own value chain or pay extra to the publishing house. We estimate that only a tiny fraction of first scholarly books in the German-language area receives a service comparable to the developmental editing that Anglo-American university presses have traditionally employed, working closely with authors on the transition "from thesis to book". This certainly reflects the obligatory aspect of publishing the thesis in the German sphere, but also has to do with the situation of the scholarly book market being highly saturated.

Germany has an exceptionally high ratio of scholarly presses to active scholars, with around 600 publishers offering scholarly content, often with specialized programs, resulting in $92 \%$ of them being small enterprises with less than 12 staff. $^{6}$ Overall, the number of newly

6 http://www.boersenverein.de/de/293243. 
released titles (cf. Annual DNB 2013, 2014 and 2015) continues to grow, while retail prices have continued to rise and print runs to become shorter (see Greco and Wharton 2008). We consider this to be a shift in professional publishing from depth to breadth, meaning that the necessarily limited capacities of a professional press have to be distributed over a growing number of titles, as the attention of consumers (and the budgets of libraries) becomes ever scarcer resources for which publishers must compete. Taken together, these aspects leave the vast majority of book publishers dependent on subsidies organized by authors and editors. Hence, seen from the economic perspective of a publishing house mainly relying on sales revenues, allocating resources to the improvement of individual content (e.g., to the "thesis to book" process or the German "Lektorat") always has to be balanced against investment in dissemination and retail.

Unlike in the U.S., it is the norm in Germany that most ${ }^{7}$ authors and editors need to subsidize their specialized academic books at publishing houses, regardless of those publishers' positioning along the spectrum, as the potential markets for non-English books serving niche audiences are too small. ${ }^{8}$ These funds often come from research grants, from private foundations or research budgets or, in the case of the first book, often from the author's own pockets, and are considered to be normal practice without any stigma attached. So in German-language humanities and qualitative social sciences authors and editors generally expect that they must subsidize almost all of their book projects serving the "peer-to-peer communication" function within their discipline, such as classical monographs with a narrow focus, conference proceedings or thematic anthologies, reference works for experts, projectrelated research results or the aforementioned doctoral thesis. Nevertheless, most book projects of commercial publishers will demand exclusive rights and rarely offer them within a dedicated digital strategy, but instead they maintain a revenue model dependent on print retail. This corresponds to the generality of authors, editors, and pub-

7 To our knowledge up to now there are no studies giving robust evidence on the ratio of subsidized vs. unsubsidized monographs published for the German language area.

8 As a rough estimation an average scholarly monograph (b/w only, around 250 pages, medium copy-editing and formatting effort) requires around 300 non-discounted sold copies on top of author's, class or review copies to break even (personal communication with Manchester and Amsterdam University Press, 2012 and Akademie-Verlag 2013). The vast majority of German language titles never reach these sales numbers. Reasons are small markets, niche audiences, tight library budgets, unbridled growth of new releases, and further fragmentation of scholarly disciplines and discourses. lishers displaying strong and at times seemingly ideological reservations regarding innovative approaches such as open access, even though the benefits for public dissemination, and therefore impact, may seem obvious.

We should also note, with regard to the German context in particular, that while language serves as a descriptive carrier of information in the humanities and qualitative social sciences, just as it does in the natural sciences, in the former it functions as well as both as a research subject in itself and as an analytical, interpretive tool for frequently hermeneutic approaches, in addition to those of cultural setting and contextualization. The straightforward use of a lingua franca such as English, now common in the natural sciences, is thus hardly an option for scholars working both in and with the German language. This dependence on the vernacular drastically reduces the potential market for publishers in comparison to the sciences. Given the lower distribution density of authors and publishers in the respective disciplines, it becomes clear why the dovetailing of research output and the corresponding dissemination format poses a general challenge here, and especially for the "long argument," the monograph. The example of Germany might highlight this dilemma. The market for scholarly books in German is large enough for publishers to stay in business with conventional modes of publishing (including the mentioned subsidies from authors), yet not limited enough to force those book publishers into seeking out new opportunities in online dissemination or open access publishing models.

To sum up, we can state that any doctoral candidate in Germany should be able to find some affordable publishing option for her or his dissertation along the spectrum that seems to be widening in the last years. Nevertheless, getting tenure as a young researcher in the German-language area is as challenging as in the Anglo-American sphere, and the first book and the reputation of its channel tend to shore up conventional evaluation and publishing modes. But the situation does not seem to be as tight as it is for early-career researchers in the U.S. or U.K. competing with each other for the scarce publishing options in highreputation Anglo-American university presses as a prerequisite for tenure.

\section{University presses in the United States}

U.S. universities began providing publishing services in the form of university presses in the second half of the $19^{\text {th }}$ century. Today, the Association of American University 
Presses (AAUP) has about 140 member presses, $85 \%$ of them at U.S. institutions. ${ }^{9}$ Cornell University Press was the first American university press, having been founded in 1869, with Cornell's first University Librarian as its director. ${ }^{10}$ Cornell Press only operated for fifteen years in its first instantiation, however; it was re-established in 1930 and has been in continuous operation since. The direct tie between the Press and the Library did not survive into the $20^{\text {th }}$ century. Johns Hopkins University Press, founded in 1878, has the distinction of being the oldest, continually functioning American university press. As Peter Givler recounts, many of the country's most prestigious universities - private and public - established presses between 1890 and 1920 and there was a steady growth of new presses in the decades following. Both university presses and libraries experienced tremendous growth in the 1960's as a boom in U.S. government funding for higher education in the context of Cold War competition fueled a massive increase in scholarly production. ${ }^{11}$ The growth period of U.S. university presses in the twenty-five years following the Second World War brought a shift of focus for the presses from publishing primarily authors from their home institutions to lists made up mainly of external authors. This wider and more competitive terrain tended to raise publishing standards and involve the university presses and their authors more intensively in an economy of prestige. ${ }^{12}$ Presses' outward orientation also distanced editorial decision-making from universities' internal campus politics and potential pressures surrounding the work of local authors, fostering more objective and unbiased evaluation processes.

Funding tightened again for universities during the 1970's, which resulted in declining library budgets and a corresponding drop in book sales. Institutional subsidies to university presses began to diminish in the same decade and as a result, presses were increasingly expected to make their own way in closer proximity to market forces, to function partly as independent entities, partly as university units. Perhaps ironically, it is in this same period, as book sales began to trend downward for the university presses, that the role of the published book was consolidated as a standard requirement for tenure in the humanities and social sciences at U.S. research universities, driven by the increasingly competitive market for academic jobs. ${ }^{13}$

9 The AAUP provides a "snapshot" of data on member presses: See at the AAUP website http://bit.ly/2wd5qQI.

10 Okerson and Holzman (2015) 2-3.

11 Givler (2002); See at the AAUP website http://bit.ly/2fMEel2.

12 See Meisel (2010).

13 Stanton et al. (2006).
The dynamic of shrinking sales to libraries and declining subsidies from the parent institutions has continued ever since, accelerated by the shift to digital and the various ways this has affected both libraries and presses. The rapidly expanding share of library budgets taken up by mainly commercial serials in recent decades has sharply cut into the acquisition of university press books. Robert Darnton, historian and former University Librarian at Harvard University, illuminates the cascading effects of this scholarly communications problem:

\footnotetext{
"Owing to the skyrocketing cost of serials, libraries that used to spend 50 percent of their acquisitions budget on monographs now spend 25 percent or less. University presses, which depend on sales to libraries, cannot cover their costs by publishing monographs. And young scholars who depend on publishing to advance their careers are now in danger of perishing." 14
}

Darnton links the fates of three academic stakeholders: libraries, university presses, and scholars - in particular young scholars facing tenure decisions that will likely depend on a university press publishing their books. Darnton's analysis echoes a report by the Modern Language Association of America (MLA) from 2006, addressing the state of scholarly book publishing in the context of tenure review (and the need to reform that process). The MLA report (2006) noted that market pressures on university presses have led to the publication of fewer specialized titles, which in turn raises the specter of a "narrowing of publishing possibilities, especially in fields viewed as marginal." The authors of the MLA report looked forward to the emergence of alternative, electronic channels for delivering specialized scholarship - and notably recommended that university presses and libraries work together on developing alternative publication channels.

In fact, over the past decade, various forms of librarypress collaboration or convergence have been increasingly proposed as a way out of the impasse faced by scholarly book publishing in the current model. A particularly influential set of recommendations was offered in a 2007 report on "University Publishing in a Digital Age," published by Ithaka, a not-for-profit research and consulting service on issues in higher education and scholarly communication. The Ithaka Report called for universities to embrace a broad and robust publishing role as part of their "core mission," coordinating and strengthening existing publishing activities that most universities already support in fragmentary fashion. The library and the university press were envisioned as two key components (among others) of

14 Darnton (2009). 
this broad "university publishing" model. Importantly, the Ithaka Report provided detailed reflection on the "different and often complementary strengths and weaknesses" of academic libraries and university presses, characteristics that might exist in tension, but that "could be harnessed to deliver a compelling new publishing enterprise."15

The story of the changing press-library relationship in the U.S. over the past decade can be viewed as a part of a return trajectory for the university presses: from an internal, institutional focus to a self-standing, external orientation, and the long road back. Though not the first university press to move within the administrative oversight of the library, the University of Michigan Press's restructuring as a unit of the University of Michigan Library in 2009 gained a great deal of attention, because it was explicitly and publicly discussed as a move that would "relieve[...] the press of pressure to be financially self-sustaining." Success would be measured not by sales, but by the press's ability to serve the University's mission within an annual budget, like other academic units. ${ }^{16}$ Today, the University of Michigan Press is one component of Michigan Publishing, based in the Library, which offers a broad suite of publishing and consultation services to University of Michigan authors and operates the institutional repository. Michigan stands out as one of the most closely integrated of U.S. press-library consolidations, but in these days a growing number of American University Presses report administratively to their institution's library, at least 19 according to a 2014 count. In some cases the relationship is largely an administrative formality; in others it amounts to a true operational merger. ${ }^{17}$

In tandem with the reorientation of U.S. university presses, U.S. academic libraries are playing an increasingly visible and formal role as scholarly publishers. While American libraries have been active over the past two decades in establishing institutional repositories for open access dissemination of scholarship and some have had more developed publishing programs, a new assertiveness and sophistication is evident in even the past four or five years. 2014 saw the establishment of a new institutional membership organization, the Library Publishing Coalition (LPC), with a mission to foster "the development of innovative, sustainable publishing services in academic and research libraries to support scholars as they create, advance, and disseminate knowledge." ${ }^{18}$ The LPC includes 66 member libraries - all in U.S. except for one in Canada,

15 Griffiths et al. (2007).

16 Howard (2009).

17 Okerson and Holzman (2015) 18.

18 See http://www.librarypublishing.org/about-us/mission. one in Chile and, with University College London, one member in Europe. It holds an annual Library Publishing Forum and publishes annual Library Publishing Directory highlighting publishing activities in 106 college and university libraries from the U.S. and Canada plus 12 from Australia and Europe in the 2017 edition. By 2015, LPC had begun to accept members from outside of North America, auguring well for stronger intercontinental cooperation in coming years. The establishment of the LPC was hailed as a signal of "the coming of age of library publishing activity" in a 2015 report on The Once and Future Publishing Library (Okerson and Holzman; this document might itself be viewed in a similar light). While cooperation between libraries and university presses is not the central focus of the LPC (whose members include libraries from many institutions that do not support a university press), it has cultivated these relationships. Last year, AAUP and LPC introduced a grants program to facilitate their members attending each other's conferences. ${ }^{19}$

\section{University presses in Germany}

In Anglo-American countries, the publishing profile of university presses is often based on thematic specialization and selectivity, which is one factor in limiting the ratio of internal to external authors and editors. As a group of publishers, despite their differences in size or organization they serve as an essential venue for scholarly books in the English-speaking world. The German case is different. University presses today play a subordinate role in scientific book publishing; their contribution in journal publishing is even more negligible. This has to do with their specific history. The German university presses have evolved in three "waves." The "first wave" took place during the Enlightenment age in tandem with the founding of the respective universities. Renowned commercial publishing houses currently in operation, such as Herder for Freiburg or Vandenhoeck \& Ruprecht for Göttingen, started their enterprises in the 18th century as their respective university's printer with exclusive rights and evolved into indispensable partners in the value chain of scholarly communication. They were meant to operate as economically independent and therefore needed to maintain control of what they published. Consequently, universities did not brand these publishing houses and were not able to shape the respective publishing programs directly.

19 See at the AAUP website http://bit.ly/2x9iqn0. 
The "second wave" of university presses falls into the late mid-20th century and the expansion of the German academic system, and led to university presses finally being named as such. The oldest dedicated university press still in operation started 1969 (the Universitätsverlag der Technischen Universität, Berlin). Another example is the University of Architecture and Civil Engineering (Bauhaus-Universität) in Weimar, situated in the socialist German Democratic Republic, when it founded its press in the late 1950's for efficient dissemination of research results in architecture, engineering, and history of architecture. The Bauhaus-Unversitätsverlag survived through German unification until 2014 when the press had to close down due to budget cuts in the higher education sector in the federal state of Thuringia. Also worth mentioning is the Carl von Ossietzky University of Oldenburg, established in 1973, which founded its university press (now known as BISVerlag Oldenburg) in 1979 as an integral part of the university's Library and Information System (BIS) ${ }^{20}$ from the start.

The "third wave" is closely tied to electronic publishing and the internet, allowing university libraries to embrace new distribution modes for electronic information and offering local services to foster open access publishing. Several university libraries started their presses as part of their aim to establish open access in the scholarly communications landscape. They followed policy recommendations of the Science Council in July 2001 and the German Rectors' Conference 2002, recommending universities to start their own publishing infrastructures such as repositories and university presses. ${ }^{21}$ University presses of that "digital generation" include Kassel University Press (1997), Universitätsverlag Potsdam (1998), Hamburg University Press (2002), Universitätsverlag Karlsruhe (2003), Universitätsverlag Göttingen (2003), Universitätsverlag der TU Berlin 2004, Bamberg University Press (2007), among others. To our knowledge, there are 33 university presses in the German language area, 25 of them members of the working group of German-language university presses "AG Universitätsverlage", ${ }^{22}$ all of the latter with an open access policy in place and none of them with a

20 The library's director Hermann Havekost, stated already in 1984 that the Library and Information System had to efficiently support researchers throughout the entire value chain of science, namely from reading to writing. To date BIS-Verlag has published around 2,350 publications such as monographs, proceedings, book series, journals, and digital publications, most of them with parallel, free, and immediate online publication of its print products.

21 Pampel (2006) 29.

22 See the website of the working group http://bit.ly/2ic6LkR. dedicated aim to keep the ratio of internal to external authors and editors low. On the contrary, these presses are in place to distribute their own faculty's research, and therefore reflect the research profile of their host universities. Member presses are under control of the university, sometimes organized as a service unit, sometimes as an embedded commercial unit with its own legal status.

The working group consists of press representatives willing to collaborate, based on common values and rationales, but without a legal status. Sharing those values is a prerequisite for collaboration; the values express the overall mission of universities becoming active in publishing themselves. Member presses are expected to have the overt recognition of their home institution, an affinity to open access and a licensing policy in place that encourages reuse and further dissemination, while having various measures in operation to ensure high quality of their scholarly content (internal or external reviewing, quality management, professional dissemination, etc.). As university presses in the German-language area will have different degrees on economic independency from their home institution, the working group agreed on a mandatory business model for members that are based on partnership with authors and editors instead of profit-maximizing. Therefore, member presses do not consider each other competitors and agree to collaborate in a transparent and collegial manner. For the time being, member presses share the trait that their target authors and editors are mainly members of their home institution or they cover subjects the home institution has a focus on.

The average annual output of the aforementioned presses are 44 book titles per year in a hybrid model, combining small print runs in high-quality print-on-demand with free online versions. Journal publishing is still negligible. These university presses usually operate with around two full time equivalent direct staff, often supported by other service units from the university or library (accounting, HR, logistics). Most presses are in control of their income and have to cover part of their costs, ranging between the requirement to cover production costs as well as all personnel and overheads costs. All member presses of the working group publish open access, more than half of them make it mandatory for authors and editors. Most presses are defined to serve the public (meaning the public institution) and therefore enjoy fiscal privilege $(58 \%$ of member presses do not pay income tax). For the case of Göttingen University Press the tax privilege is justified by the fact that researchers at the university are faced with strong open access policies, either from funders such as the European Commission or 


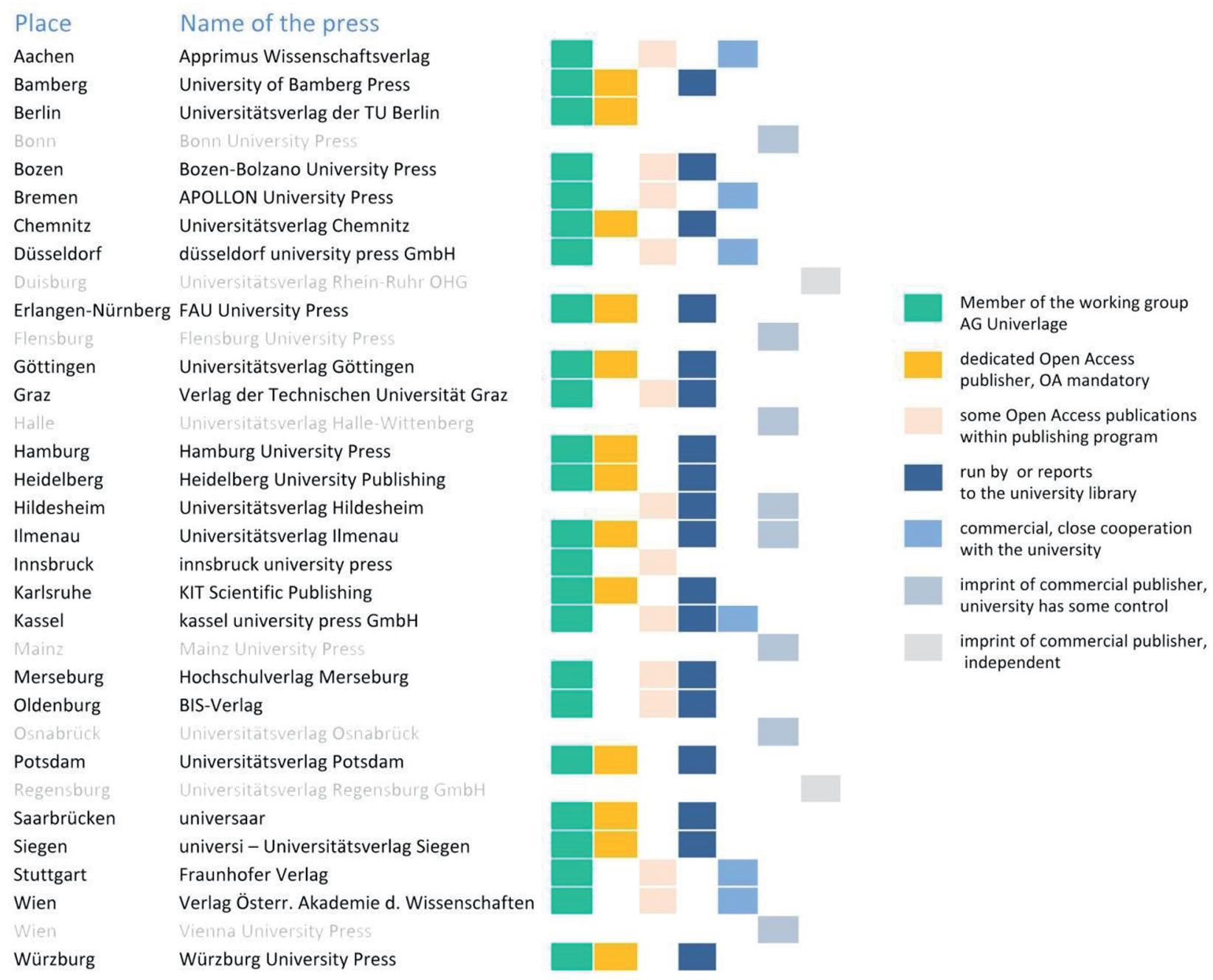

Fig. 2: Overview of German University Presses

the German Research Foundation (DFG) and therefore need affordable publishing options in open access with professional publishing services of a press (quality control, reviewing, branding, and dissemination via trade and online) that comply to expectations of their respective disciplines. Authors and editors at Göttingen University Press have stated repeatedly that the conditions in the commercial publishing sector have turned more problematic over the years: continued refusal of liberal reuse or open access rights, waxing prices, and waning quality of service and products.

The vast majority of the mentioned university presses are embedded in a wider service portfolio to offer innovative and sustainable publishing services. Often they belong to departments in charge of repositories such as dissertation servers or institutional repositories, open access publication funds or open access offices. Their existence reflects the fact that research libraries with digital technologies at hand are no longer "containers of established knowledge", but they changed into active partners of creation and production of knowledge, while European funders and policy-makers continue to move research and its infrastructures towards open access and Open Science.

\section{University publishing at University of Göttingen}

The university library in Göttingen has been a pioneer in the support of researchers with innovative services for decades. The current library website states:

"Göttingen State and University Library, founded in 1734, was the first realization of the idea of a modern research library. As 
early as the 18th century, the library began developing holdings of national and international importance, which were continuously maintained throughout its history. Based on these efforts, the library has taken on a variety of tasks at the local, regional, national, and international level. [...] Göttingen State and University Library contributes and provides sustainable and free access to the scientific and cultural digital memory and encourages the use of its collections by researchers, educators and the general public. It supports the protection of intellectual property, the right to privacy and data protection, accessibility and multilingualism. The library is dedicated to improving the visibility of Göttingen University's research output as well as its cultural heritage. In addition to providing content and infrastructures, the library is committed to fostering information and media literacy practice.”23

Already in the early 1990s, Göttingen's library director Elmar Mittler shared the vision with other contemporaries that in the digital age any scientific result should be available publicly and that distinguishing its quality it should be realized on the consumption side and organized through platform functionalities, instead of selectivity in the conventional publishing paradigm and resulting artificial shortage of access. ${ }^{24}$ Consequently, research institutions and libraries started to provide infrastructures for authors to upload and archive digital research results, which allow easy access and usually open retrieval. These infrastructures drew on concepts of the preprint cultures (e.g. physics) and meant to offer reliable infrastructures for publications otherwise considered to be preliminary or informal. Applying their usual processes, university libraries started to 'insource' publishing to some extent by making sure that informal or preliminary publications were citable, accessible and presented within collections, based on strategy and policies. Such an insourcing process inevitably led to responsibilities beyond access to information that previously had been taken care of by an external expert system of presses and publishers.

The University of Göttingen was among the first signatories of milestone initiatives such as the Berlin Declaration; Göttingen researchers received an exceptionally early and strong share of open access advocacy based on a university management commitment that research funding should encompass dissemination of research results and respective funding for the necessary infrastructure. But if digital storage and open access was to reach full coverage over and acceptance from all disciplines, there had to be specific publishing services for all faculties in

23 https://www.sub.uni-goettingen.de/en/about-us/portrait/. $24 \operatorname{Mittler}(2003) 118$. place. That was the logical conclusion among high-level decision makers such as the library directorate and the university management. It became evident that the library would not be able to fill such a new role sufficiently if the publishing activities did not reflect on the 'certification' function of publishing, such as discipline-specific reward systems, resulting expectations about branding, quality control and reviewing processes. For scientific articles in journals, the digital transformation came up with remarkable speed and success, as the format was easily adaptable for digital processes. Even large commercial stakeholders moved in the same direction.

For books and the disciplines relying on them as a communication format, the digital transformation could seem less promising than disruptive and even risky. Therefore, Göttingen University Press initiated new book publishing models (print on demand in small print runs, digital production, open access combined with books for sale) and trustworthy publishing services for their own faculties and individual researchers. To ensure trustworthiness, the press has an editorial board with active professors representing each faculty. The board acts as a steering committee for the press's mission and strategy, and the involved professors function as editors and reviewers for the published subjects as well.

The press resides within a wider service portfolio, which includes open access repositories for electronic theses and dissertations, informal or preliminary works (working papers, reports, etc.) and retrodigitized publications. We regard these publishing options as direct publishing services. In such direct services the library takes an active role in the production or re-opening of scholarly content, which entails responsibility for the content itself: its accessibility, its archiving, but also quality control and compliance with discipline-specific standards and expectations. To support researchers and faculty throughout the entire value chain of scholarly and scientific communication, library additionally runs several indirect publishing services. That means, the library is not involved in direct content production, but supports authors and editors with consulting, financing (e.g., open access publication fees), or infrastructure. In the case of parallel open access, i.e., open dissemination of content that is also published in a fee-based version. Clearly, there is an overlap between direct and indirect publishing services. Whether offered by open access publishers, repositories that support self-archiving by authors, or in the context of national licenses, the infrastructure for parallel open access publications is theoretically detached from content production. However, these open access versions of scientific content are often the only ones freely or even digitally 
available, moving the library, when it is the infrastructure provider, into the role of a downstream publishing agent. Consulting for university affiliates (students, early-career researchers, faculty members, scientific managers) mostly takes place around publishing contracts, costs of publishing and intellectual property rights such as reuse and licensing, either through individual consulting or lecture and training formats. Fortunately, university members are becoming more aware that interaction with commercial publishers has become more complicated and challenging in the digital era and that it makes sense to reach out for advice from internal experts such as the library's publishing unit.

Göttingen's publishing services are embedded in a strategic engagement in national and international initiatives, such as the working group for German-language university presses mentioned above, the Association of European University Presses (AEUP), Open Access Scholarly Publishers Association (OASPA), the Confederation of Open Access Repositories (COAR), and several projects under the umbrella of OpenAIRE, the European-wide open access infrastructure for publications and the European Commission's open access and open science policies. Being active in these initiatives enhances local services on one hand; on the other it provides a means for influencing future policies and legal or political frameworks. Being a consortium member of the EU-funded project HIRMEOS ${ }^{25}$, for instance, will improve the technical platform of the press via default use of DOIs and ORCID or text and data mining for entity recognition. At the same time, the consortium will analyze disciplinespecific delays, obstacles or prejudices about open access to pave the way for widest possible uptake of open access book publishing.

\section{University publishing at Cornell}

While the new German university presses were largely born in libraries as a centralized institutional response to scholarly communications issues in the digital era, in the U.S., as outlined above, university press and library publishing activity has mostly followed separate trajectories though with key points of intersection and, increasingly, a tendency toward convergence. The term "university publishing," associated with the 2007 Ithaka report cited above, encompasses a broad spectrum of formal and infor-

25 High Integration of Research Monographs in the European Open Science infrastructure: https://www.hirmeos.eu/. mal publishing based in the academic institution. The Ithaka model was an aspirational one, envisioning a close coordination of publishing work among various academic units, including (but not limited to) university presses and libraries. We use the term here more loosely and more empirically. We offer a brief and selective profile of publishing activities at Cornell University in Ithaca, New York, focusing on library-press collaboration, which at Cornell is a matter of only limited coordination. As noted above, Cornell is home of the first university press established in the United States. Cornell University Press (CUP) publishes around 120 new book titles each year, largely in the social sciences and humanities, but with an important science list as well; CUP does not currently have a full journals program (although it has recently assumed publication of two journal titles). Cornell University Library (CUL) has also been a pioneer in developing and hosting alternative publishing venues. Cornell presents an unusual library publishing case: CUL began this work early and has established maintained some particularly high-profile publishing initiatives over time, but the library has been less active in recent years in starting new publishing initiatives, while these have begun to proliferate at other institutions. The library co-developed (with Pennsylvania State University Libraries) DPubS, the electronic publishing software system that underlies Project Euclid, the publishing platform in mathematics and statistics launched in 2003 that CUL hosts in partnership with Duke University Press. ${ }^{26}$ Project Euclid hosts 73 journal titles, several books and proceedings series published by not-for-profit mathematical societies and university math departments from around the world, some open access, and some available via subscription. Project Euclid is robust library-press collaboration, but notably one that is dispersed between two institutions.

Since 2001, CUL has been the home of arXiv, the open access "e-print server" that is an absolutely essential component in the worldwide scholarly communications networks in the fields it serves: Physics, Mathematics, Computer Science, Quantitative Biology, Quantitative Finance, and Statistics. ArXiv reached one million articles in 2014 and now receives around 9,000 article submissions per month. In 2010, CUL and CUP launched a book series in the field of German Studies, Signale: Modern German Letters, Cultures, and Thought, which is co-published by the press and the library, in partnership with Cornell's College of Arts and Sciences, in print and electronic form. Signale was a direct response to the "narrowing of pub-

26 See Ehling (2005). 
lishing possibilities" for academic publishing in the humanities, described in the 2006 MLA report cited above. At least three longstanding book series in the field published by other university presses were discontinued in the first decade of the 21st century. German Studies is a relatively small field in the U.S., but particularly strong and vital at Cornell. The Signale program benefits from an unusual division of labor among staff at the library and the press and a strong local faculty editorial board. The intensive involvement of local scholars in the publishing process and the alignment of the series with a key academic strength of the institution made the work and the stakes of humanities publishing more visible in the University community. The Signale program's attention to sustainability has helped both the library and the press to better understand and control publishing costs. Signale books shift to open access four years after initial publication.

\section{Solutions at scale?}

We have described broad trends that are driving changes to traditional models of scholarly book publishing in the U.S. and German contexts, and we have looked at initiatives that are evolving at individual institutions and groups of institutions to create new models. We turn now to some ambitious proposals and initiatives that have emerged in the past 3 or 4 years that seek high-level solutions to the impasses faced by scholarly book publishing.

In 2014, the Association of American Universities (AAU) and the Association of Research Libraries (ARL) released a proposal for a nationally-coordinated and standardized program of subsidizing publication costs for faculty members' first books in fields where tenure is dependent on book publication. The "AAU-ARL Prospectus for an Institutionally Funded First-Book Subvention" seeks to maintain the current American system in which university presses compete for high-quality manuscripts beyond their own institutions, but to strengthen and improve the system with a more rational and sustainable funding model. In the proposed subsidy structure, authors' institutions would cover publishing costs for books selected according the presses' editorial standards, rather than commercial viability. While the minority of U.S. universities that operate presses today bears an undue financial burden for benefits that flow in large part to authors at other universities; a standardized subsidy structure could balance the burden among institutions. And with return of publishing costs ensured in advance, the books published in this model could make openly accessible online without threatening cost recovery. ${ }^{27}$

A number of initiatives emerged in the wake of the AAU-ARL Prospectus that complement its objectives and some could help lay the groundwork for something like the model the Prospectus envisions. The Andrew W. Mellon Foundation, an essential force in scholarly communications reform in the United States, has renewed its focus on the university presses, awarding a series of capacitybuilding grants in 2015 to support components of an improved and more open infrastructure for publishing digital scholarship in the humanities. ${ }^{28}$ The Mellon Foundation also funded complementary research on the true costs entailed in publishing scholarly monographs and the implications for open access options, ${ }^{29}$ as well as on book subventions in institutional context. ${ }^{30}$ In March 2017, AAU and ARL, together with the Association of American University Presses (AAUP), announced the open access Monograph Publishing Initiative, based on the 2014 Prospectus, including a "funding model based on publication grants," and intended "to advance the wide dissemination of scholarship by humanities and humanistic social sciences faculty members by publishing free, open access, digital editions of peer-reviewed and professionally edited monographs." ${ }^{31}$ At this early date, 12 U.S. universities have committed to participate in the program by providing publication grants and nearly 60 university presses in the U.S. and Canada have committed to publish open access books in this framework. It remains to be seen how broad and how lasting an impact the initiative will have.

We have also begun to see new open access monograph implementations at individual university presses (like California's Luminos program ${ }^{32}$ ) or in multi-press bundles delivered by third parties (e.g., Knowledge Un-

27 Task Force on Scholarly Communication (2014). The Prospectus is based on a white paper prepared by publishing consultant; see Crow (2012). In 2014, the Mellon Foundation solicited a study of potential implications at a single university of an institutional funding model for humanities monographs. The report, based on the reflections of faculty and administrators at Emory University, provides an excellent overview of how a university-funded publication model might be executed at a U.S. research institution and potential impacts on various facets of the scholarly communication environment; see Elliott (2015).

28 Straumsheim (2015).

29 Maron et al. (2016).

30 Hilton et al. (2015).

31 Shore et al. (2017).

32 http://www.luminosoa.org/. 
latched ${ }^{33}$ and MUSE Open ${ }^{34}$ ) that focus squarely on university presses' publishing costs and cost recovery.

Open access book publishing is one of the key features of the university presses in the German-language area. What these presses have in common are their challenging early years that made them turn to the working group for guidance, practical support or exchange of experience. The fact that, in starting a press, the host institutions were extending their range of services into areas of competence that up to that point had been exclusively occupied by commercial players meant that each of the new presses faced the challenge of being judged against the standards of that commercial field. However, research institutions established their presses not just to offer new services, but precisely to challenge the status quo of an increasingly dysfunctional balance among research institutions, libraries and commercial players.

Nevertheless, most of the new presses had to start understaffed, underfunded and experimental - they had to develop their processes on their own due to their innovative approach and unprecedented publishing model. They had to struggle with prejudices, whether from the conventional publishers, which tended to view the new university presses as illegitimately subsidized competitors, or from scholars who frequently felt that the presses would downgrade book publishing, force open access on disciplines or publish secondary results of questionable quality. Several presses had to argue with university administrations that the presses to be self-sustaining while offering high quality and reputation for the institution. The prejudices - or misunderstanding - of scholars and university administrations, we believe, stemmed from the fact that most presses grew out of library-based publishing units in charge of dissertation platforms, repositories or printing services. We postulate that library efforts especially in the digital field often seem to be taken for granted or go largely unnoticed as the objectives of these efforts are seamless user experiences and work relief, backed up by digital processes designed to be as unobtrusive as possible. At the same time, researchers are familiar with publications, but only a fraction fully understand publishing, which can lead to an

33 See http://www.knowledgeunlatched.org/. Note that the University of Michigan Library is the U.S. base for Knowledge Unlatched, a not-for-profit company based in the U.K., see at the library's website http://bit.ly/2v6vSXp.

34 With support from the Mellon Foundation, Project MUSE at Johns Hopkins University Press is developing a platform to host open access monographs from multiple university presses and scholarly societies. See https://www.press.jhu.edu/news/announcements/mellon-foun dation-fund-muse-open-new-oa-platform. overestimation of conventional publishing stakeholders and the confusion of digital dissemination with a lack of quality, or else to an underestimation of the level of competence or professionalism it takes for good publishing services; so expectations of the success of new library services and the required resources at times were fairly unrealistic. It has to be emphasized that these new presses in the German language area did a remarkable job in squaring the circle of becoming professional publishers with inadequate means, challenging the status quo of a professional publishing system that wouldn't offer open access book publishing to scale. Had they failed, we believe, it would have led to reputation losses that especially institutions with a history of high reputation usually avoid.

Therefore, we take it as a promising sign that the existing presses almost all gain momentum in their institution and in the disciplines, and that one of the oldest German universities, namely Heidelberg (founded in 1386, press founded in 2015), has accomplished its innovative library-based publishing services ${ }^{35}$ with a university press. Heidelberg has launched the press after several years of successfully running digital publishing on the local level for all university faculties and on the national level for art history and archaeology, resulting in a high degree of support for discipline-specific publication cultures.

The question remains, why the uptake of open access and, indeed, of electronic publishing more broadly -, continues to be fragmented and delayed in the book-oriented disciplines. Particular writing and reading habits, the reputation economy, and storage concepts in the humanities and social sciences pose significant challenges to all stakeholders involved. And if stakeholders have less room to move - whether for economic reasons or reasons of professional identity - there will be little change on the supply side for digital books. Low numbers on the supply side, however, mean that the acceptance of the new and unfamiliar will accordingly also remain low.

Consequently, open access book publishing is taking place either in mission-driven university presses like in the German case, at innovative publishers such as Ubiquity Press $^{36}$ that act as a service provider to several library publishing initiatives or Open Book Publishers, ${ }^{37}$ and also with a handful of commercial presses at the upper price level. Worth mentioning are the efforts of aggregating plat-

35 http://heiup.uni-heidelberg.de/about_us/mission_statement. $36 \mathrm{http}: / /$ www.ubiquitypress.com/, the business model requires author contributions starting at 3,400 GBP for a monograph of medium size.

$37 \mathrm{http} / / /$ www.openbookpublishers.com/, prizes in a comparable range to Ubiquity Press. 
forms such as OpenEdition with their innovative "freemium" model (free HTML open access plus paid access to PDF and mobile formats) and the OAPEN library hosting around 2,300 freely accessible books in 14 languages. MUSE Open, mentioned above, which is based at Johns Hopkins University Press and aggregates open access eBooks from various university presses and other publishers as well as the multi-publisher open access eBook program at JSTOR are also relevant here. The majority of small and medium-sized commercial players seem to lack proven business and revenue models and experience, while the costs in recent commercial offerings such as Springer Open $^{38}$ or Palgrave Macmillan ${ }^{39}$ clearly show that the publication supply in the open access model cannot be left entirely to market forces. The promotion of the open access monographs of the Austrian Science Fund ${ }^{40}$ is an example of creating incentives for commercial publishers ${ }^{41}$ to offer open access publishing options. It remains an open question whether such funding schemes will truly have a transformative effect on the publishing ecosystem or merely create windfall gains for authors or editors and their respective publishers. So far, in book-oriented disciplines we still lack an adequate supply of literature in the open access mode per se. Improving this state of affairs would require a stronger push for more open access, despite the successful work of the aforementioned players.

Emerging in distinct higher education landscapes, the convergence of library and university press publishing in Germany and, to a certain extent, in the United States has responded to some disparate and some similar challenges. Certainly, the two experiences can be mutually illuminating and library and university press publishing in both national contexts would benefit from more dialogue and information sharing. Fortunately, dialogue of this kind would seem to be increasing. In May 2016, a high-level summit in Philadelphia, convened by the Association of

$38 \mathrm{http} / /$ www.springeropen.com/books. Usually quoted as $€ 15,000$ in presentations given by Springer representatives.

$39 \mathrm{http} / / /$ www.palgrave.com/open/faq.asp\#section2. The projected costs are within the realm of up to $€ 14,000$.

40 http://www.fwf.ac.at/de/projects/selbststaendige_publikationen .html.

41 In the program referred to, the support funds available are some $€ 14,000-€ 20,000$ for a hybrid publication. In the case of the majority of publishers, this would allow an open access option while eliminating practically all risk. The question of whether a publicly funded risk insurance for the private sector, which in large part consists of for-profit institutions, is both a desirable and/or an inevitable effect of such a program could not be fully answered due to the natural limitations of the project's brief. This facet, however, could be pursued in further dedicated research projects.
Research Libraries (ARL), the Association of American University Presses (AAUP), and the Coalition for Networked Information (CNI), brought together library and press directors who share an administrative relationship to discuss issues of common concern. While most of the participants were from U.S. and Canadian institutions, Wolfram Horstmann, Director of Göttingen State and University Library and chair of the editorial board of Göttingen University Press, presented a European perspective ${ }^{42}$ that shed some light on reasons for the specific European developments in institutionally-based and usually mission-driven publishing.

In his talk, Horstmann emphasized a political climate in Europe in favor of in-house university publishing, mentioning prominent examples such as the relaunch of University College of London Press, ${ }^{43}$ established 2015 as a library service unit, and Stockholm University Press (2013), also run by the university library. He outlined the mutual benefits of a professionally-run, in-house press for the host institution and the library (e.g., branding advantages, broadening of service portfolio, and proximity to faculty), but also pointed out weaknesses and risks of embedded publishing enterprises, which require careful efforts to reach sustainability. Most of these challenges involve obvious issues such as quality control, business and revenue models, and cost structure and licensing. Others require deeper strategic thinking: defining the relationship between the host institution and its press; agreeing on purpose and rationale; developing governance structures and procedures that account for the taxpayer's role of financing such services at public institutions. Horstmann's outlook for the research monograph and its yet-tobe-developed full potential focuses on two important aspects. One is that the current, conventional publishing system poses dilemmas of career isolation, especially for innovative researchers working in the digital humanities with its new forms of research output such as digital editions, enhanced publications, data-rich monographs, and fluid texts. The other aspect is that much of this innovative research will remain invisible and unavailable for current scholarship if they must pass through the bottleneck of conventional publishing in order to be eligible for recognition, certification or tenure.

42 See Muccie et al. (2016).

43 Article from Paul Ayris, UCL head librarian, and Lara Speicher, publishing manager of UCL press (2016). 


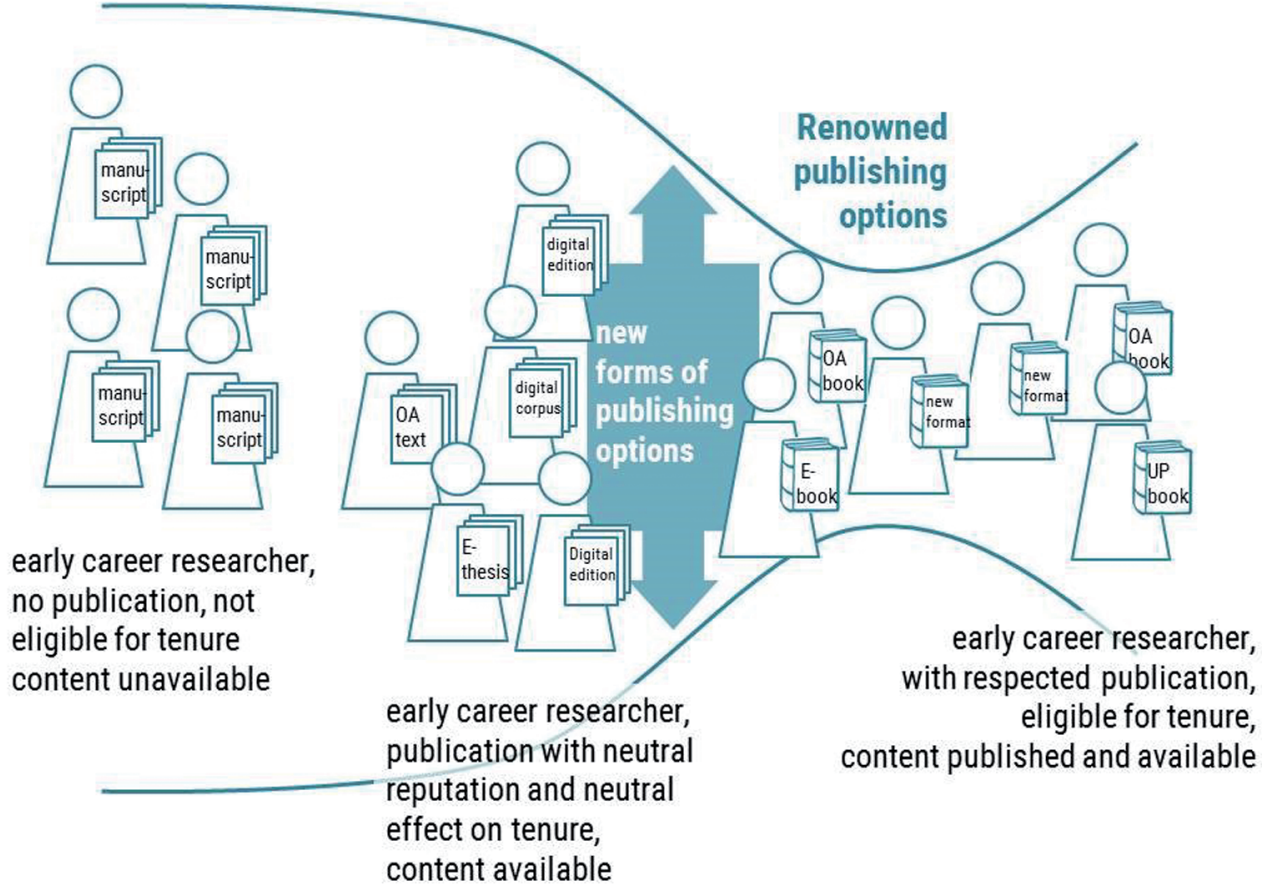

Fig. 3: Publishing options in the wake of digital publications and open access

\section{Conclusion}

Widening the bottleneck by building appropriate alternatives decreases the pressure on all stakeholders, not just authors and readers, but also not-for profit publishers, like the university presses in the Anglo-American field forced to be largely self-sustaining by recovering costs through sales. Widening the bottleneck can also help to establish innovative forms of research output as part of the canon of publication, offering new possibilities for researchers and authors. But only by ensuring that more and more published research becomes available on an open access basis the full potential of these publications can be realized - for the producers of the content and for those interacting with it. The German example suggests that mission-driven, inhouse, library-based publishing services have distinct advantages in reaching these objectives. Their embeddedness, closeness to faculty and their ability to draw on institution-wide synergistic effects allow them to act as incubators for new revenue models or cost structures, as well as innovative content types. Research processes and research output in the humanities and qualitative social sciences are undergoing a process of profound transformation. If publishing in these domains is to keep pace, it must change in an agile fashion, incorporating new requirements and possibilities, without losing sight of the broader objectives of scholarship. The flexible in-house steering being pioneered in the new German university presses has the potential to facilitate such an agile expansion, as long as institutions are prepared to allocate the necessary resources.

While many of the same dynamics are in play in the U.S. context, the American case is different in key respects from the German one. The sheer heterogeneity of U.S. research institutions (some public, some private; some large, some small; some well-endowed, some less so) makes it difficult to propose universal solutions. The publication bottleneck, especially in the sense of the "narrowing of publishing possibilities" noted by the MLA and referenced above, can have a deleterious effect on the production and dissemination of scholarship. Yet at the same time, the selectivity of the U.S. university presses is tightly linked into the scholarly value chain in the humanities and many of the social sciences. The rich traditions of established university presses, the role of particular presses and their book lists in shaping the development of academic fields and schools of thought well beyond their home campuses, the certification and prestige function of the university press imprimatur are widely valued by scholars.

But here, too, there is a partial shift of focus toward authors on the home campus at many university presses; this responds partially to a growing expectation that presses have to demonstrate their worthiness to local stakeholders, but it also reflects a desire to effect changes in a scholarly communication system in which the sustainabil- 
ity of the monograph is in question. The benefits of embeddedness outlined for the German context apply in the U.S. as well. Libraries, already embedded in campus life in a way that most presses have not been for decades, can appear to be natural partners in this regard. Along with U.S. libraries' expanding publishing role, we are witnessing an increasing alignment of library and university press publishing - whether this is achieved through administrative merger and restructuring, a coordinated division of labor within an overarching university publishing strategy, or through loose library-press partnerships. While it is still in its early development, the AAU-ARL-AAUP Open Access Monograph Publishing Initiative represents a partnership of research libraries, university presses, and academic authors at the level of national professional associations. Notably, the initiative would seem to seek to preserve the distinctiveness of the U.S. university press landscape with its outward focus, its competitive aspect, and its selectivity - while relieving pressures around publishing costs and opening access. Building organically, in this way, on facets of the system that are valued by scholars seems particularly promising for the U.S. context.

Scholarly book publishing faces similar pressures in the United States and Germany. The academic contexts and the publishing and library landscapes have much in common and share close institutional, cultural, and historical ties. Yet different points of departure for universitybased publishing and divergent sources of funding and policy decisions for higher education between the two countries has led to somewhat different approaches to questions of scholarly communication, including the relationship of the library and the university press to book publishing. We are convinced that these differences - in many cases subtle ones - as well as the many similarities in the problems we face and solutions we propose, make German-U.S. dialogue around this issue potentially especially fruitful.

\section{References}

AAUP Library (2013): AAUP Library Relations Committee, Press and Library Collaboration Survey. AAUP. Available at http://www.aa upnet.org/resources/for-members/data-collection-and-analy sis/library-press-collaboration-survey.

Adema, Janneke (2010): Overview of Open Access Models for eBooks in the Humanities and Social Sciences. OAPEN Deliverable public report. Available at http://project.oapen.org/images/docu ments/openaccessmodels.pdf.

Ayris, Paul; Speicher, Lara (2015): UCL Press: the UK's 'first fully open access' university press. In: Insights, 28(3) 44-50. DOI: http://doi.org/10.1629/uksg.257.
Careno, Angela et al. (2015): New Platforms and Discovery Tools: Toward 21st-Century University Presses and Libraries. In: Proceedings of the Charleston Library Conference. Available at http://dx.doi.org/10.5703/1288284316237.

Clement, Gail P.; Rascoe, Fred (2013): ETD Management and Publishing in the ProQuest System and the University Repository: A Comparative Analysis. In: Journal of Librarianship and Scholarly Communication, (1.4), eP1074. DOI: http://doi.org/10. 7710/2162-3309.1074.

Crow, Raym (2012): A Rational System for Funding Scholarly Monographs. November 2012. Available at http://www.arl.org/sto rage/documents/publications/aau-arl-white-paper-rational-sys tem-for-funding-scholarly-monographs-2012.pdf.

Dallmeier-Tiessen, Sünje; Lengenfelder, Anja (2001): Open Access in der deutschen Wissenschaft - Ergebnisse des EU-Projekts 'Study of Open Access Publishing' (SOAP). In: GMS Med Bibl Inf, (11) 1-2. Doc03. doi:10.3205/mbi000218.

Darnton, Robert (2009): Google and the Future of Books. In: New York Review of Books. Available at http://www.nybooks. com/articles/archives/2009/feb/12/google-the-future-ofbooks/.

Ehling, Terry (2005): DPubS: The Development of an Open Source Publishing System. In: Publishing Research Quarterly, 20 (4) 41-43. DOI: doi:10.1007/s12109-005-0047-0.

Elliott, Michael A. (2015): The Future of the Monograph in the Digital Era: A Report to the Andrew W. Mellon Foundation. In: Journal of Electronic Publishing, 18 (4). DOI: http://dx.doi.org/10.3998/33 36451.0018.407.

Givler, Peter (2002): University Press Publishing in the United States. In: Scholarly Publishing: Books, Journals, Publishers and Libraries in the Twentieth Century, ed. Richard E. Abel and Lyman W. Newman. New York: Wiley, 107-120.

Greco, A.N.; Wharton, R.M. (2008): Should University Presses Adopt an Open Access [Electronic Publishing] Business Model for All of Their Scholarly Books? In: Proceedings of the 12th International Conference on Electronic Publishing, 'ELPUB2008, Toronto. Open Scholarship: Authority, Community, and Sustainability in the Age of Web 2.0', ed. by L. Chan and S. Mornati, 149-164. Available at http://elpub.scix.net/data/works/att/149_elpub2008.content. pdf.

Griffiths, Rebecca J.; Rascoff, Matthew; Brown, Laura; Guthrie, Kevin M. (2007): University Publishing in a Digital Age. Ithaka S + R. Available at https://doi.org/10.18665/sr.22345.

Hahn, Karla L. (2008): Research Library Publishing Services: New Options for University Publishing. Washington, D.C.: ARL. Available at http://www.arl.org/storage/documents/publications/re search-library-publishing-services-mar08.pdf.

Hilton, James et al. (2015): A Study of Direct Author Subvention for Publishing Humanities Books at Two Universities: A Report to the Andrew W. Mellon Foundation by Indiana University and University of Michigan. University of Michigan Deep Blue. Available at http://hdl.handle.net/2027.42/113671.

Howard, Jennifer (2009): U. of Michigan Press Reorganizes as a Unit of the Library. In: Chronicle of Higher Education. Available at http://www.chronicle.com/article/U-of-MichiganPress/47128.

Maron, Nancy L.; Mulhern, Christine; Rossman, Daniel; Schmelzinger, Kimberly (2016): The Costs of Publishing Monographs: Toward a Transparent Methodology. Ithaka S+R. Available at https://doi. org/10.18665/sr.276785. 
Meisel, Joseph S. (2010): American University Presses, 1929-1979: Adaptation and Evolution. In: Book History, (13). Available at www.jstor.org/stable/40930531.

Mittler, Elmar (2003): Libraries and International Infrastructure for Open Access Services. In: Information Services \& Use, (23) 117-118.

Muccie, Mary Rose; Lucia, Joe; Shore, Elliott; Lynch, Clifford; Berkery, Peter (2016): Across the Great Divide: Findings and Possibilities for Action from the 2016 Summit Meeting of Academic Libraries and University Presses with Administrative Relationships (P2L). White paper. ARL. Available at http://www.arl.org/component/c ontent/article/6/4163.

Muller, Nadine (2016): Writing for Survival: Publishing \& Precarity in the Lives of Early-Career Researchers. Conference slides. University Press Redux Conference (16-17 March 2016) at Liverpool University Press in association with the Academic Book of the Future project. Available at https://liverpooluniversitypress.co. uk/pages/university-press-redux-slides.

Okerson, Ann; Holzman, Alex (2015): The Once and Future Publishing Library (Washington, D.C.: Council on Library and Information Resources). CLIR pub 166. Available at https://www.clir.org/pub s/reports/pub166.

Salisbury, Leila, et al. (2014): What's the Big Idea? Mellon, ARL, AAU, University Presses, and the Future of Scholarly Communication. In: Proceedings of the Charleston Library Conference. Available at http://dx.doi.org/10.5703/1288284315623.

Shore, Elliott; Sebeok, Jessica; Berkery, Peter (2017): AAU, ARL, AAUP to Launch Open Access Monograph Publishing Initiative Project Will Share Scholarship Freely, More Broadly. Association of Research Libraries. Available at http://www.arl.org/news/arlnews/4243-aau-arl-aaup-to-launch-open-access-monograph-pu blishing-initiative-project-will-share-scholarship-freely-more-br oadly\#.WPWYIHpSe9t.

Stanton, Domna C. et al. (2006): Report of the MLA Task Force on Evaluating Scholarship for Tenure and Promotion. Modern Language Association of America. Available at http://www.mla. org/tenure_promotion.

Straumsheim, Carl (2015): Piecing Together Publishing. In: Inside Higher Education. Available at https://www.insidehighered.co $\mathrm{m} /$ news/2015/02/25/researchers-university-press-directors-em boldened-mellon-foundation-interest.

Task Force on Scholarly Communication (2014): AAU-ARL Prospectus for an Institutionally Funded First-Book Subvention. Task Force on Scholarly Communication, Association of American Universities (AAU) and Association of Research Libraries (ARL). Available at www.arl.org/publications-resources/3280-aau-arl-prospec tus-for-an-institutionally-funded-first-book-subvention.

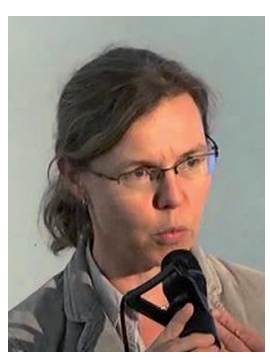

\section{Margo Bargheer}

Georg-August-Universität Göttingen

Niedersächsische Staats- und

Universitätsbibliothek Göttingen

D-37070 Göttingen

mbarghe@gwdg.de

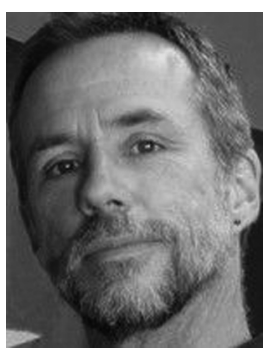

\section{Kizer Walker}

Director of Collections

Cornell University Library

309 Uris Library

Cornell University

Ithaca, NY 14853

USA

kw33@cornell.edu 